ments " with subsequent improvement to about $1 / 60$ in a good light.* It was thought that the galyl had some beneficial eftect in checking the disease, and the following additional remedies were all tried without any great success : Locally, atropin followed by eserin on account of the rise of tension, and later, dionin, hot fomentations and compresses, leeches to the temple, massage through the closed lids in the later stages: by mouth, salicylates for a mouth followed by perchloride of mercury, together with mercurial inunctions, and later hypodermic injections of pilocarpine in increasing doses daily, for ten days. Eventually the active trouble slowly subsided, the injection and pain disappeared, and when last seen in February, 1919 , the eye was quite quiet, tension about normal; there was a partial red reflex and he could just see to read and write letters in a good light : the chief cause of the poor vision then appeared to be organised inflammatory exudate in the pupil. No definite "keratitis punctata" ever appeared in this eye.

I wish, in conclusion, to thank Major A. W. Ormond for putting these cases at my disposal.

\title{
AN EPIDEMIC OF MACULAR KERATITIS
}

\section{BY \\ H. KIRKPATRICK, MADRAS.}

CASES of a peculiar form of keratitis have been seen for the past eighteen months in Madras with increasing frequency until in September of this year the disease has assumed an epidemic character, two or three fresh cases being met with every day.

The type of keratitis somewhat resembles superficial punctate keratitis, but differs in some respects from descriptions of that disease, being distinctly more macular than punctate in character. It has taken three main forms in all of which the opacity appears to be situated in the superficial layers of the substantia propria, Bowman's membrane, and the deeper layers of the corneal epithelium. In none of these does the corneal surface stain with fluorescin.

The symptoms complained of are loss of vision, the appearance of a white spot on the cornea, and occasionally lacrimation and irritation.

The first type is a superficial punctate keratitis and in it small

${ }^{*}$ Since the foregoing was written the patient has been seen on August 28, 1919. V. was then "fingers at 3 feet," eye not injected but painful at intervals; anterior chanber almost non-existent, tension raised, partial red reflex. I fear that he will probably lose what vision he has owing to the secondary glaucoma. 
opaque spots, varying in size from a pin point to a large pin's head, are seen dotted irregularly over the surface of the cornea. These number from three to twelve and do not appear to be more common in one part of the cornea than another. The patient naturally complains more when a spot is situated in the pupillary area, and some irritation may be present, should one lie near the limbus. The spots usually have a soft edge and seldom show any elevation of the surface; any loss of polish is rare. The absence of any vascular reaction, either conjunctival or circumcorneal, is astonishing.

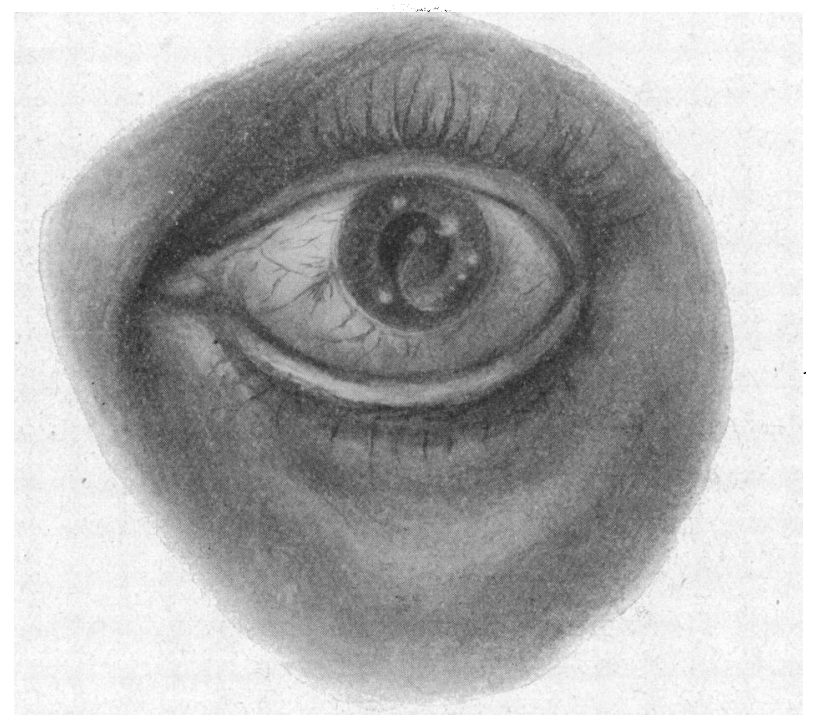

Intermediate between. I and II.

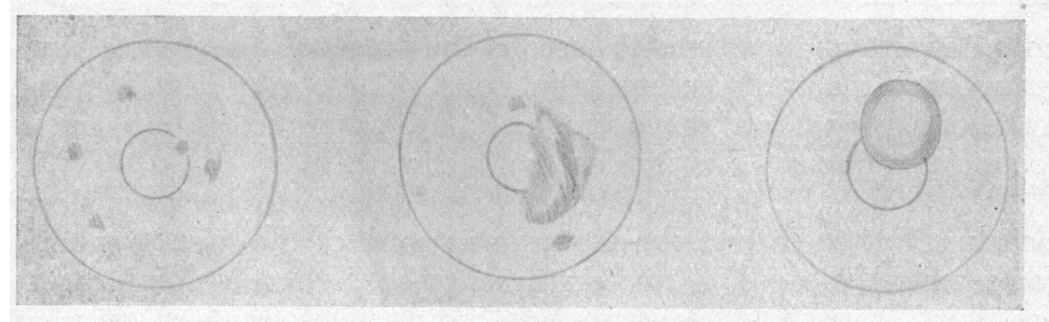

No. 1.

No. 2.

No. 3.

In the second type a large patch is found, the general punctate character being lost. This nearly always șhows a denser part which is often linear and sometimes raised, and from this the. soft opacity fades away into the healthy tissue on either side. The 
patch is often shaped like the nucleus of a myelocyte, the indentation being placed on the fainter edge. One or two soft detached spots are frequently found in the neighbourhood of the large area and occasionally a small spot may be seen at some distance from it. The size of the large patch generally is as large as a quadrant of the cornea. In the later stages the surface of the area usually becomes dulled. This type is the one most frequently met with.

The third type shows a single spot only; this is dense, sharply circumscribed, and often slightly raised. Its surface may lose its polish at a fairly early stage and slight vascularization may occur if it is placed near the limbus. Its edges are denser and more distinctly raised than the centre. It causes more irritation than the other types and is more obstinate in clearing up. The patch is generally smaller than that found in the second type.

In none of these types is it possible to say that one part of the cornea is more affected than another, although in the second and third forms, the edge of a lid sometimes corresponds to a border of the opaque area. The lids and conjunctiva are perfectly normal and free from congestion as a rule, but occasionally there may be some slight congestion in the last two types; still this absence of vascularity is most surprising and is one of the striking features of the disease. It is very rare for the disease to attack more than one eye.

No opportunity to obtain a specimen of the entire thickness of the cornea in an affected area has yet occurred, but deep scrapings have been made frequently. From these and from the general appearances it is evident that only the superficial structures of the cornea are involved. Major Cunningham, I.M.S., of the King's Institute of Preventive Medicine, has kindly made several examinations of these scrapings, and numerous cultures have been made by him and his staff, but all have proved negative bacteriologically and in no case have organisms resembling those described by Herbert* in Bombay, or any other variety, been found. Inflammatory cells are exceedingly scarce in the specimens and the only definite change seen hitherto is the presence of numerous small granules in many of the epithelial cells. These granules often seem to be of a very faint brown tinge and are extranuclear but arranged around the nucleus and in close contact with it.

As a rule the opacities have been found to be very slow in. clearing, but their duration is variable; some of the first or punctate variety have cleared in two or three weeks, whereas some cases of the third type have been under observation for over a year and; though considerable absorption has taken place, have not completely cleared yet. A local superficial necrosis is occasionally seen in the late stages of the two last varieties, but no secondary infection with corneal ulceration has occurred up to date.

${ }^{*}$ Ophthal. Rev., 1901, p. 339. 
The disease has been met with in all classes of the populationwell-to-do Indians, coolies, workmen of all classes, merchants, and Europeans of good station. Age does not appear to have any influence in its causation, although it has been seen most frequently between 25 and 45 . Considerably more men than women have been attacked, but the male out-patients always outnumber the female. Patients have not come from any one house or street, nor does any one part of the town appear to be specially affected. No case coming from outside the Madras area has been seen as yet. Some of the Madras streets have been tarred recently, but most patients have not lived in the vicinity of such roads, nor have they passed along them on their way to work. The patients have all appeared to be in reasonably good health, and though many have suftered from influenza, the proportion of such is no greater than might have been anticipated in view of the wide-spread sharacter of the recent epidemic. No association with any other general disease has been apparent and the epidemic has not been accompanied by any rise in frequency of herpetic conditions of the cornea.

The salient features in the aetiology of the disease are : first, that the number of cases met with is sufficient to constitute a mild epidemic; secondly, the apparent absence of bacteria or other organisms ; thirdly, the singular lack of local reaction ; fourthly, the apparent absence of contagion (so far I have not known a patient admit that another member of his household is or has been aflected nor have any of the Hospital staff been attacked); fifthly, its uniocular character ; sixthly, the absence of any general disease or constitutional defect in patients attacked. Thus it will be seen that the problem is not a very easy one to solve. Presumably the cause is either parasitic or nutritional. Its uniocular character and the general good health of the patients make it difficult to believe that it is nutritional. If parasitic it is unlikely to be bacterial as some bacterial organism would probably have been found in the fresh or stained specimens examined, or in one of the numerous cultures made, and, under the circumstances, I can only suggest that protozoa which have escaped observation may be the cause of the disease.

Many different drugs and forms of treatment have been tried, but as yet no useful specific line of treatment has been discovered. Some of the better class of patients have benefited by change of air, but this had no effect upon others. Ethylhydrocuprein and quinine have apparently been of use occasionally, but in other cases have had no effect. Lymphagogue treatment has been tried extensively, but has been disappointing on the whole. The routine treatment now adopted is the use of eyebaths of magnesium sulphate in concentrated solution, combined with exposure of the 
area to the heat of the actual cautery, which is approached as close as possible to the surface of the cornea without actually touching it ; the cautery should be held in position long enough to excite a mild reaction.

I have only been able to find very scanty descriptions of the disease described by Herbert as occurring in epidemic form in Bombay, but apparently this epidemic is closely allied to it. It differs from the descriptions I have seen in the character of the maculae, and in its intractability as well as in the absence of bacteria.

Since writing the above a patient, who was in the same wards as sufferers from the complaint, has developed the disease in a previously healthy eye. This is the first occasion on which any evidence of contagion has been apparent.

\title{
NOTES ON A RARE FORM OF SUBCONJUNCTIVAL. GRANULOMA MET WITH IN CENTRAL CHINA
}

\author{
BY \\ P. L. MCALl, B.A., M.B., Ch.B., \\ LONDON MISSION, HANKOW.
}

THERE are seen from time to time in Central China patients whose eyesight is obstructed, entirely or partly, by the formation of tumourlike masses which grow between the eyeball and the lid. There is no conjunctivitis or other acute inflammation. The growths are painless; they do not ulcerate on the surface or break down in the centre, but remain firm throughout. They gradually involve the eyelids, producing great thickening, which finally causes the mechanical occlusion of the palpebral aperture.

The writer has seen about a dozen cases of this condition. The patients varied in age from 15 to 40 years, the majority being men. One or both eyes may be involved, the duration of the case ranging between one and a half and nine years.

The usual progress of a case is as follows: The growth commences as a rule near the inner canthus (rarely under the outer half of the upper lid), as a firm, fleshy thickening and protrusion of the conjunctiva. The protrusion is reddish in colour and not oedematous, and forms flat or rounded and nodular masses, one-eighth to one-half inch in extent, which interfere with the accurate closure of the lids. The conjunctiva does not move on the surface of the growth, but is closely adherent to it. The growth then spreads around the inner surface of the lids, involving the upper and lower fornices and making a heavy nodular curtain 